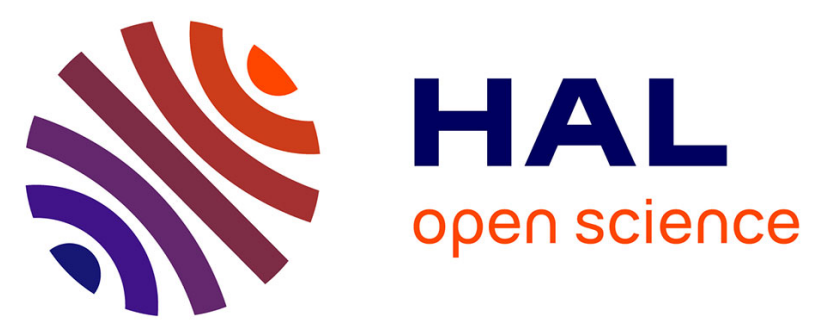

\title{
Self-Regulated Learning Processes Vary as a Function of Epistemic Beliefs and Contexts: Mixed Method Evidence from Eye Tracking and Concurrent and Retrospective Reports
}

Gregory Trevors, Reza Feyzi-Behnagh, Roger Azevedo, François Bouchet

\section{To cite this version:}

Gregory Trevors, Reza Feyzi-Behnagh, Roger Azevedo, François Bouchet. Self-Regulated Learning Processes Vary as a Function of Epistemic Beliefs and Contexts: Mixed Method Evidence from Eye Tracking and Concurrent and Retrospective Reports. Learning and Instruction, 2016, 42, pp.31-46. 10.1016/j.learninstruc.2015.11.003 . hal-01340592

\author{
HAL Id: hal-01340592 \\ https://hal.science/hal-01340592
}

Submitted on 20 Mar 2019

HAL is a multi-disciplinary open access archive for the deposit and dissemination of scientific research documents, whether they are published or not. The documents may come from teaching and research institutions in France or abroad, or from public or private research centers.
L'archive ouverte pluridisciplinaire HAL, est destinée au dépôt et à la diffusion de documents scientifiques de niveau recherche, publiés ou non, émanant des établissements d'enseignement et de recherche français ou étrangers, des laboratoires publics ou privés. 
Self-Regulated Learning Processes Vary as a Function of Epistemic Beliefs and Contexts:

Mixed Method Evidence from Eye Tracking and Concurrent and Retrospective Reports

Gregory Trevors ${ }^{1, *}$

Reza Feyzi-Benagh ${ }^{2}$

Roger Azevedo ${ }^{3}$

François Bouchet ${ }^{4}$

${ }^{1}$ Department of Educational Psychology, University of Minnesota, United States

${ }^{2}$ Department of Educational Theory\&Practice, State University of New York, United States

${ }^{3}$ Department of Psychology, North Carolina State University, United States

${ }^{4}$ Laboratoire d'Informatique de Paris 6, Université Pierre et Marie Curie, France

Revised version : 25 November 2015 


\begin{abstract}
The objective of the current studies was to investigate how epistemic cognition related to specific phases and components of self-regulated learning and its adaptation to learning conditions of varying quality. In a multi-study, mixed method design, we presented university students with science content that relayed conceptual discrepancies and collected quantitative and qualitative data to study how students responded to discrepancies. In Study $1(n=42)$, we collected eye tracking patterns, study times, and metacognitive ratings and found that participants adapted their behavioural processing as a function of their epistemic cognition and discrepancy type. In Study $2(n=20)$, we collected concurrent think-aloud protocols and retrospective interviews to further explore why discrepancies were noticed (or not) and how they were resolved. Results revealed that prior knowledge and epistemic self-efficacy in oneself as an evaluator of knowledge emerged as important themes to detecting and efficiently resolving discrepancies. We conclude with a discussion of theoretical and methodological implications.
\end{abstract}

Keywords: epistemic cognition; self-regulated learning; metacognition; process data. 


\section{Introduction and Theoretical Frameworks}

Individuals in the $21^{\text {st }}$ century who have access to increasingly complex, ill-structured, and evolving information are presented with new challenges to quality learning (Sinatra, Kienhues, \& Hofer, 2014). This is especially true within the context of self-authored, Web 2.0 online content that is oftentimes not regulated by traditional "gate-keepers" and which may relay misinformation (Farrell, 2015; Kata, 2012; Lewandowsky, Ecker, Seifert, Schwarz, \& Cook, 2012). Thus, chief among these challenges to learning is refining digital literacy skills, such as planning, monitoring, and evaluating the use of learning strategies (i.e., self-regulated learning; Azevedo et al., 2012, 2013; Trevors, Duffy, \& Azevedo, 2014) and assessing the accuracy of new knowledge and integrating its multiple sources (i.e., epistemic cognition; Greene, $\mathrm{Yu}, \&$ Copeland, 2014). Facets of self-regulated learning and epistemic cognition are also closely linked constructs core to science literacy (Barzilai \& Zohar, 2014; Zohar \& Barzilai, 2013; Muis, 2007). Together, skilled self-regulation and the development of new literacies empower individuals to make informed decisions about medical treatments, controversial climate policies, or healthy lifestyle choices, among other important personal and global issues with a scientific basis.

Across many studies, individuals' beliefs about knowledge and knowing - their epistemic beliefs - and the self-regulation skills they enact during studying are known to separately relate to learning and achievement (Azevedo et al., 2012, 2013; Bouchet, Harley, Trevors, \& Azevedo, 2013; Bråten, Anmarkrud, Brandmo, \& Strømsø, 2014; Feyzi-Behnagh et al., 2014). However, what remains relatively unknown are specific empirical relations between self-regulated learning and epistemic cognition, particularly in conceptually rich computer-based learning environments of varying quality. Thus, we currently report on two studies wherein we experimentally manipulated the inclusion of discrepant information to induce active repair processing and 
observed the relations between epistemic cognition and key aspects of self-regulation while individuals studied science content.

In the first section, we describe theories of self-regulated learning, including frameworks that integrate epistemic cognition (EC) and self-regulated learning (SRL). Next, we review early empirical evidence for the influence of SRL and EC on learning from conceptually rich computer-based learning environments. Then we review theoretical frameworks and evidence to understand the effects of conceptual discrepancies on SRL and EC to inform the hypotheses of the current study.

\subsection{Self-Regulated Learning}

Students' regulation of their learning processes is a critical determinant of academic achievement, particularly in conceptually rich multimedia environments (Azevedo, 2014, 2015; Greene, Moos, \& Azevedo, 2011). Increasingly, learners are confronted with substantial amounts and multiple representations of information (e.g., text and graphs). These conceptually rich multimedia learning environments are often delivered online and offer learners access to important, complex, and evolving information. However, these environments may have multiple, questionable, and/or contradictory authors. In the face of potentially discrepant information, learners must enact skilled SRL processes to set appropriate learning goals, efficiently navigate across content, select relevant and reliable texts, diagrams, and learning strategies, and continually monitor and evaluate their emerging comprehension against their goals and constraints (e.g., time, conflicting sources). Failure to enact skilled SRL may diminish, or in the context of questionable discrepant content, jeopardize quality learning from these multimedia environments. Hence, inherent in effective learning from contemporary multimedia learning environments is an active and goal-directed process by learners to monitor and control their 
cognition, metacognition, motivation, affect, and behavior in a manner that is sensitive and adaptive to specific features of learning contexts (Azevedo et al. 2012, 2013; Bannert \& Mengelkamp 2013; Opfermann et al. 2013; Pintrich, 2000).

We use SRL theories to understand and predict the complexity and patterns of these learning processes within multimedia environments (Azevedo et al., 2012, 2013; Greene \& Azevedo 2009). In particular, we make the assumption that SRL occurs as a series of events unfolding across time and adopt Winne and Hadwin's $(1998,2008)$ information-processing model of SRL. Therein, Winne and Hadwin proposed SRL to occur in four weakly sequential and recursive phases: 1) defining a learning task; 2) making goals and plans; 3) enacting learning strategies; 4) adjusting strategies through metacognitive monitoring. Within and across each of these phases are information-processing activities that occur during each phase and are responsible for movement between phases.

In the first phase of SRL, individuals form a perception of the task at hand, which may significantly differ from one learner to the next. For example, one student may define their task to be to understand all they can about climate change, whereas another may define their task to achieve some minimum grade on a subsequent test. In the second phase, individuals develop multifaceted learning goals, such as completing their task by a certain time or meeting a standard for understanding instructional content, and then form plans to achieve these various goals. In the third phase, individuals carry out their plans by enacting learning strategies, such as re-reading, paraphrasing, coordinating multiple sources of information, or generating inferences. In the fourth phase, individuals metacognitively reflect on their learning processes from phases 1 through 3 and use information gained from this reflection to regulate subsequent actions. If, for example, an individual judges her learning progress to be acceptable, she proceeds unabated. 
However, if she judges that her learning progress is not satisfactory, whether it is in terms of spending too much time on one aspect or not meeting some standard for comprehension, she may decide to exert control through modifying aspects of subsequent definitions, goals, plans, or enacted strategies. Thus, central to this fourth phase is the recursive nature of Winne and Hadwin's $(1998,2008)$ model, as what metacognitive information is attended to by individuals affects all learning processes that follow. Taken together, Winne and Hadwin $(1998,2008)$ describe optimal SRL overall as exemplified by efficient movement between the four phases that is contingent upon monitoring and regulation of information-processing.

Indeed, one hallmark of SRL is the assumption that skilled learners will be adept at monitoring (themselves and the content) so that they can use information gained from activity to decide how to proceed next in their learning. Investigations into metacognitive monitoring is a burgeoning area of research and has highlighted the importance of several judgments learners will make while studying, including prospective ease-of-learning judgments (EOL), concurrent judgments of learning (JOL), and retrospective confidence judgments (RCJ) (Bjork, Dunlosky, \& Kornell, 2013). The primary function of such judgments is to allow individuals to select what content to study and efficiently allocate study time across learning material (Dunlosky \& Metcalfe, 2009). EOLs represent judgments made prior to starting and thus reflect the preparatory phases of SRL (e.g., task definitions, planning). JOLs represent learners' subjective self-evaluation of how well the content is learned and have important implications for study time allocation (Dunlosky \& Metcalfe, 2009). Last, RCJ represent how confident the learner is that he or she performed well on a test of learning.

Researchers attempt to describe learners' overall strategy or agenda for studying. In one such theoretical account by Metcalfe (2002), she proposed that learners will allocate limited 
study time to content perceived to be the easiest to learn. Referred to as the region of proximal learning model, learners will triage their scarce study time to content deemed to provide the greatest opportunity for learning. In addressing the question of learners' perseverance on tasks, Metcalfe and Kornell (2005) further proposed a new metacognitive marker that reflected an active, process-oriented approach to JOL. They theorized that learners will make judgments about the rate of learning (jROL) and will continue to study until they judge that the rate of knowledge acquisition has reached a standstill, or determine that some low criterion value reflecting diminishing returns have been met, at which point they will stop. In sum, metacognitive judgments made before, during, and after learning have important implications for what to study, how to study it and for how long, and thus reflect core phases and constructs of SRL. Although many factors affect students' performance at self-regulating (Azevedo et al., 2012), in the current research we propose that learners' tacit beliefs about the nature of knowledge, or epistemic beliefs, are an active and influential learner characteristic affecting SRL as it unfolds (Bromme, Pieschl, \& Stahl, 2010; Muis, 2007).

\subsection{Epistemic Cognition}

We investigate EC under the multidimensional framework (Hofer \& Pintrich, 1997; Stahl \& Bromme, 2007). Individuals may believe knowledge to be isolated facts (i.e., simplicity dimension) that, once discovered, remain unaltered by time or human intervention (i.e., certainty dimension). To learn such knowledge requires careful attention and memory to those who discovered it - experts and authorities in various fields - as the nature of knowing is believed to be a faithful reproduction of relayed facts (i.e., source and justification dimensions). In contrast, epistemic cognition may also broadly comprise beliefs that knowledge is a network of interconnected facts. Such knowledge is believed to be updated over time with additional 
reasoning and new evidence. Rather than the source and justification for knowing stemming from expert testimony, these individuals believe the nature of knowing to require personal justification; to not only accurately recall a knowledge claim, but to be able to understand and evaluate the reasons and evidence in support of that knowledge claim (Muis, 2007). We adopt the terminology from other researchers (e.g., Muis et al., 2015) and refer to constructivist epistemic cognition as comprising of beliefs in complex, unstructured, subjective, and dynamic knowledge congruent with a constructivist epistemology (Sawyer, 2006). In contrast, we refer to less constructivist epistemic cognition as comprising of beliefs in simple, structured, objective, and static knowledge. ${ }^{1}$

However, there is controversy in the field of epistemic cognition on the psychometric soundness of traditional methods of measuring EC. Extensive reviews of the psychometric properties of common EC self-report instruments have shown unstable factor structures and at times unacceptable reliability (DeBacker, Crowson, Beesley, Thoma, \& Hestevold, 2008; Welch \& Ray, 2012). Further, insights from cognitive interviewing of participants' interpretation of EC questionnaires have also raised doubts of their validity (Greene, Torney-Putra, \& Robertson, 2010; Greene, Yu, \& Copeland, 2014; Muis, Duffy, Trevors, Ranellucci, \& Foy, 2014). As Pieschl et al. (2014) note, these psychometric issues may be due to the possibility that not all participants have explicit-denotative knowledge of their epistemic cognition.

On the basis of this reasoning, Stahl and Bromme (2007) developed the Connotative Aspects of Epistemological Belief (CAEB) questionnaire. This semantic differential instrument consists of several antonym adjective pairs that reflect associative-connotative assumptions of knowledge and knowing (e.g., dynamic - static; Pieschl et al., 2014). This instrument produced

\footnotetext{
${ }^{1}$ We choose not to use the labels "naïve" and "sophisticated," although frequently used in the past by researchers, to avoid making an evaluative commentary.
} 
two reliable dimensions: beliefs about the Texture of knowledge (e.g., whether knowledge is assumed to be unstructured, ambiguous, and subjective) and beliefs about the Variability of knowledge (e.g., whether knowledge is assumed to be dynamic, uncompleted, and open). These dimensions share conceptual overlap with simplicity and certainty dimensions, respectively (Hofer \& Pintrich, 1997), but the CAEB is selected for the current research given its potential to circumvent issues in traditional measurement methods.

\subsection{Relations between Epistemic Cognition and Self-Regulated Learning}

Theoretically, EC is related to SRL via the multifaceted standards learners set to achieve their learning goals (Bromme et al., 2010; Greene, Muis, \& Pieschl, 2010; Muis, 2007). Standards for learning refer to multifaceted criteria that the learner seeks to achieve while learning, such as maintaining a particular level of comprehension while reading or finishing a task at a certain time. In these models, EC shapes the standards formed during the preparatory phases prior to learning. Standards are used during metacognitive monitoring (i.e., comparing standards with cognitive products), which subsequently mediates strategy-use (Chiu, Liang, \& Tsai, 2013; Winne \& Hadwin, 2008). If, for example, a student believes that knowledge is structured and static s/he may set a standard for learning that only requires sufficient memory of a single source in isolation, which rote memorization may achieve. In contrast, a belief in unstructured and dynamic knowledge may set a standard for learning that might motivate greater effort at uncovering and understanding complex interrelations among multiple sources and attempt to integrate them.

The relations between EC and SRL may be especially important within the context of encountering and resolving discrepancies in knowledge. Such discrepancies include inconsistencies between an individual and an external source of knowledge (e.g., textbook; Kendeou, Walsh, Smith, \& O’Brien, 2014), inconsistencies between sources (e.g., disagreement 
among experts; Muis et al., 2015) or within sources (e.g., conceptual discrepancies between a text and graph; Burkett \& Azevedo, 2012). Such discrepancies put focus on questions about the structure, variability, and sources of knowledge, which likely activates individuals' epistemic cognition. Examining the effects of discrepancies on learning is particularly important given the increasing prevalence of self-authored, online content that may relay errors or misinformation (Kata, 2012; Lewandowsky et al., 2012). Successful learning is contingent on how well individuals respond to these events (D’Mello, Lehman, Pekrun, Graesser, 2014; Rapp \& Braasch, 2014). Thus, to understand how learners effectively navigate questionable content online, it becomes valuable to study the fundamental resolution strategies that individuals initiate and regulate in response to discrepancies in knowledge they encounter.

\subsubsection{Evidence for Epistemic Cognition and Self-Regulated Learning within Multimedia Environments}

There is mounting empirical evidence that $\mathrm{EC}$ is an active and influential factor during SRL within conceptually rich multimedia environments. Recently, epistemic beliefs have been found to relate to self-reported task definition, planning, enactment, and evaluation phases of SRL (Chiu, Liang, \& Tsai, 2013; Franco et al., 2012; Lee, Chiu, Liang, \& Tsai, 2014) and relate to flexibility in calibrating complex learning strategies for complex tasks during these phases as well (Pieschl, Stallmann, \& Bromme, 2014). Further, other recent studies that collected process data showed that EC is active during the process of learning with relations to computer navigation recorded in log-files (Hsu, Tsai, Hou, \& Tsai, 2014; Pieschl, Stahl, \& Bromme, 2008), concurrent think-aloud protocols (Greene \& Yu, 2014; Ferguson, Bråten, \& Strømsø, 2012; Trevors \& Muis, 2015), and attention allocation recorded by eye tracking (Kammerer, Bråten, Gerjets, \& Strømsø, 2013; Mason, Pluchino, \& Ariasi, 2014). 
For instance, Pieschl and colleagues (2014) investigated the relations between EC and adapting to tasks of varying complexity. These researchers hypothesized that less constructivist epistemic beliefs (e.g., beliefs in static and objective knowledge) will be associated with low adaptation to task complexity, whereas more constructivist epistemic beliefs (e.g., dynamic and subjective knowledge) will be associated with more pronounced adaptation. Their hypotheses were largely confirmed; learners with constructivist Texture beliefs showed an affinity for a deeper approach to learning overall (e.g., agreeing strongly that tasks involved "processing critically" and "cognitive effort"). Learners with constructivist Variability beliefs showed greater adaptation of their application of a deeper approach across all levels of task complexity (e.g., a reduced intention to enact a deep approach for memory tasks but a higher intention to enact a deep approach for creative tasks) compared to their less constructivist counterparts. Similar research showed that such metacognitive adaptation varied as a function of epistemic cognition only for tasks that are more complex but not for simpler tasks (Bromme et al., 2010).

Importantly, with regard to study time allocation and monitoring of comprehension, Pieschl et al. (2008) found that learners with constructivist EC reported lower comprehensibility ratings and spent less time on complex hypermedia pages compared to their less constructivist counterparts. In this study, the authors concluded that, paradoxically, participants with less constructivist EC seemingly calibrated more strongly to the complex learning conditions (i.e., by allocating more study time to more complex content). Pieschl et al. therefore speculated that perhaps participants with less constructivist EC were seduced by extraneous detailed information rather than more efficiently allocating limited study time to gain a more complete perspective of the content. In other words, whether learners calibrate their study time to either the immediate content or the more global and comprehensive task of learning as much as they can across all 
content seems to vary as a function of EC. This adaptation of study time appears analogous to Metcalfe's (2002) description of region of proximal learning model that likewise stipulates learners will prioritize studying content that has the greatest chance of contributing to the overall learning goal.

However, it is still not well understood how and why these relations between EC and SRL emerge or if these patterns generalize to detecting and resolving discrepancies that learners may encounter online. Thus, we examine these relations within the context of processing discrepant knowledge claims, which are likely encountered in real-world situations (Kata, 2012; Lewandowsky et al., 2012; Rapp \& Braasch, 2014) following a common experimental induction to study how learners initiate and regulate strategies to resolve resulting disequilibrium (D’Mello, Lehman, Pekrun, \& Graesser, 2014).

\subsection{Current Studies}

Central to the current set of studies is the contention that successful learning is contingent upon skilled and adaptive self-regulation of cognitive, metacognitive, and motivational learning

processes. We currently investigate epistemic cognition as one learner characteristic theorized to be influential in achieving skilled self-regulated learning. In general, we test the hypothesis forwarded by Greene et al. (2010) that aspects of learning tasks such as discrepancies can activate epistemic cognition, which in turn influence processes of self-regulated learning (Azevedo, Moos, Johnson, \& Chauncey, 2010; Greene \& Azevedo, 2009).

In the current research we report on two studies wherein we investigate the relations between epistemic cognition and several facets of self-regulated learning: metacognition, multimedia integration, study time allocation, and other active and influential cognitive and metacognitive learning strategies, as measured by concurrent think-aloud protocols and 
retrospective interviews. We investigated the following research questions: First, does learners' regulation of cognitive and metacognitive strategies vary as a function of their epistemic cognition and discrepancies? We addressed this first research question in Study 1 by observing individuals' regulation of attentional allocation and multimedia integration, as measured by eye tracking and computer log-files, and metacognition, as measured by fine-grained judgments of learning. Congruent with theoretical models and empirical findings of the relations between SRL and EC by Azevedo et al. (2012, 2013), Bromme (2010), Greene et al. (2010), Muis (2007), and Pieschl et al. (2008, 2014), we hypothesize that learners with constructivist epistemic cognition (i.e., beliefs in dynamic, uncompleted, unstructured, and subjective knowledge) will adapt their processing more strongly to pages with discrepancies than those without and in particular, consistent with Pieschl et al. (2008), in the direction of lower ratings of comprehension, less study time, and as a result, fewer attempts to integrate multimedia on pages with discrepancies that those without.

Second, if learners do regulate their cognitive and metacognitive strategies as a function of epistemic cognition as we predict, how and why does adaptation occur? We address this second research question in Study 2 by building on the findings from Study 1 through replication but with the addition of collecting concurrent think-aloud protocols and retrospective interviews to gain deeper insights to how and why patterns of relations between EC and SRL form (Van Gog \& Jarodzka, 2013). For Study 2, we did not make specific hypotheses but rather planned to explore in-depth the relations between EC and SRL observed in Study 1 through the use of a mixed method design.

\section{Study 1}

\subsection{Method}




\subsubsection{Participants}

Forty-two undergraduate students were recruited from a large, public research university in North America $(N=42)$. Thirty-one self-reported as female $(71 \%)$, eleven as male, and participants ranged in age from 18 to 26 years $(M=20.0$ years $)$.

\subsubsection{Materials}

This study extended the method of another recent study of conceptual discrepancies (Burkett \& Azevedo, 2012) and thus adopted the materials and procedure reported therein with several additions. In brief, the current study used a within-subjects design to examine the effects of three conditions of conceptual discrepancies within multimedia science content presented in a computer-based multimedia learning environment (Burkett \& Azevedo, 2012). Our unique additions to this study consisted of examination of students' epistemic cognition and eyemovements while learning.

2.1.1.1. Prior Knowledge. The general science knowledge test measured participants' prior knowledge about chemistry, physics, biology and physical science and consisted of 20 multiplechoice questions evenly distributed the four domains, which were compiled by Burkett and Azevedo (2012) from previous standardized tests (e.g., Scholastic Aptitude Test). A sample item includes: "Which of the following statements about catalysts is INCORRECT?".

\subsubsection{Connotative Aspects of Epistemological Beliefs. Stahl and Bromme's (2007)} Connotative Aspects of Epistemological Beliefs (CAEB; Appendix A) instrument was used in the current study to assess epistemic cognition, which is a 24 -item semantic differential instrument that asked participants to rate antonym adjective pairs along a 7-point scale (e.g., "dynamic" - "static") for science knowledge in general. Following Stahl and Bromme’s (2007) two-factor structure, responses to 17 items were used to assess students' epistemic beliefs on the 
Texture (10 items) and Variability of scientific knowledge (7 items), which closely but not entirely correspond to Simplicity and Certainty dimensions, respectively. Cronbach's alpha statistics for Texture and Variability were acceptable ( $\alpha=.65$ and .66, respectively; see Appendix A for the items used in the current study).

2.1.1.3. Computer-Based Multimedia Learning Environment. Participants in the current studies were presented with twelve unique multimedia content pages each relaying a different complex science topic across various domains in science (e.g., viruses; atmosphere structures; projectile motion). Each topic was described in a short text (i.e., 240 to 250 words, $M=247$ words) with a corresponding graphical representation that illustrated a concept discussed in the text. Across pages, three levels of conceptual discrepancies were presented to all participants in a repeated-measures design: No Discrepancy (ND), Within-Text discrepancies (WT; two separate conflicting sentences), and Between Text and Graph discrepancies (BTG; one text sentence conflicting with the graph trend line). The three discrepancy types were evenly distributed across the twelve pages and participants were not informed about the existence of discrepancies prior to or during the studies. For example, the page relaying content about enzymes contains a conceptual discrepancy within the text. Specifically, this WT discrepancy page relays discrepant information between the first and last sentences of the $2^{\text {nd }}$ paragraph: "Enzymes speed reactions by lowering the energy of activation, the amount of energy required to start a reaction" $[\ldots]$ By reducing the energy of activation, some enzymes decrease reaction rates a billion times" (see Figure 1). The experimental manipulation of conceptual discrepancies allowed us to examine how participants engaged in various facets of self-regulation in response to disruptions to learning and to examine how epistemic cognition relates to these SRL processes (D'Mello et al., 2014). 
2.1.1.4. Metacognition. Several measures of metacognition were obtained throughout the experimental session. Prior to accessing each page, participants were presented with an openended inference question related to the content (e.g., "What is the relationship between energy and the function of enzymes?") and were asked to provide an evaluation of the ease with which they could learn the content necessary to answer the question (Ease of Learning; EOL). Dunlosky and Metcalf (2009) have noted that the accuracy of judgments of learning significantly improves after a short delay, therefore in the current study participants were prompted to respond to JOL prompts a second time after a short delay: 30 seconds after reading and inspecting the text and graph content and prior to proceeding on to the next page, participants were prompted to provide an evaluation of their learning (Judgment of Learning; JOL) from the text and graph separately (Text JOL Text; Graph JOL Graph). A sample JOL item includes: "How well did you understand the information about the function of enzymes in the text you just read?" Then, participants provided a written response to the content question posed at the start of the content page $^{2}$. Upon completing their written response, participants were prompted to provide a final judgment of their confidence that their written response correctly and completely answers the question (Retrospective Confidence Judgment; RCJ). A sample item includes: "How confident are you that the answer you provided about energy and the function of enzymes is correct?" The completion of these metacognitive prompts represents one complete trial for one content page in the experimental session, which was repeated until all twelve content pages were processed.

Computer generated log-files recorded participants' responses to metacognitive prompts. The average metacognitive rating response was calculated for each page type (e.g., average Text JOL

\footnotetext{
${ }^{2}$ The materials we administered were more extensive than reported here; we excluded instruments from this paper if the constructs were not related our research questions. Unique research questions and data pertaining to metacomprehension are reported in AUTHORS (under review).
} 
rating for WT). From these judgment data we were able to calculate reliability coefficients, which were found to be acceptable for the ND condition (range of Cronbach's $\alpha=.60$ to .72 ) and WT condition (Cronbach's $\alpha=.66$ to .75 ) but the range for BTG showed unacceptable to substantial reliability (Cronbach's $\alpha=.30$ to .81$){ }^{3}$

2.1.1.5. Eye tracking. Tobii T-60 Eye-Tracker recorded eye fixations and movement patterns across science texts and related graphs with infrared cameras embedded in a computer monitor that displayed all content. Students' strategy-use for coordinating informational sources (COIS) was also extracted from eye-tracking data. COIS was operationalized as a sequence of two transitions between eye fixations on text and graph areas (e.g., text $\rightarrow$ graph $\rightarrow$ text), the frequencies of which were tallied for statistical analysis. We calculated the average COIS value for each of the three page types and for all pages overall.

2.1.1.6. Study time allocation. Computer generated log-files recorded the timing of participants' interactions with the system (e.g., time spent studying each content page). Study times in seconds were extracted from log-files and the average study time duration (Study Time) was calculated for ND, WT, and BTG pages.

\subsubsection{Procedure}

After completing informed consent, participants were seated in front of the Tobii EyeTracker computer monitor, which displayed the experimental content. Participants completed the prior knowledge measure, followed by the CAEB. The researcher then initiated the computerbased multimedia learning environment. The experimental session proceeded along a linear, selfpaced progression through the twelve content pages that were presented in a randomized order. The study lasted approximately two hours, for which participants were compensated \$20.

\footnotetext{
${ }^{3}$ In the BTG condition, the Cronbach's $\alpha$ reliability coefficient of .30 for Graph JOL was the outlier, which likely represents inconsistency in participants' experience of the conceptual discrepancy between text-andgraph.
} 


\subsubsection{Data Analysis}

2.1.4.1. Does learners' regulation of cognitive and metacognitive strategies vary as a function of their epistemic cognition and discrepancies?

To answer this first research question we conducted canonical correlations among sets of predictor learner variables (i.e., EC, prior knowledge) and dependent learning variables (cognitive and metacognitive strategies) for each of the three discrepancy conditions (ND, WT, BTG). To understand significant multivariate relations, we examined significant bivariate correlations among EC variables and condition-specific cognitive and metacognitive variables. Although we calculated correlations among all the variables, for ease of presentation, correlation matrices are presented separately by discrepancy condition. We wanted to apply a parsimonious analysis that maintained the comprehensive array of variables of interest and also reduced the risk of Type I error in subsequent analyses. Therefore, we interpret subsequent condition-specific bivariate correlations between EC and SRL variables as meaningful only if the related multivariate canonical correlation was significant. Finally, we determined whether the magnitude of the correlation coefficients significantly differed between discrepancy conditions.

\subsection{Results}

\subsubsection{Canonical Correlations}

Canonical correlations estimate correlations between two sets of variables by calculating a linear combination of variables within each set that forms a latent dimension, similar to factor analysis (Shell \& Husman, 2008). We calculated a canonical correlation between learning variables specific to each condition and individual characteristics. Specifically, the dependent variables were judgment of learning of text and graph comprehension, retrospective confidence 
judgments, coordinating informational sources, and time spent on pages ${ }^{4}$. The predictor variables were Texture, Variability, and to assess its effects relative to epistemic dimensions, prior science knowledge.

Of the three possible functions extracted (equal to the number of variables in the smallest set), none were statistically significant in examining the relationship between sets of variables specific to the ND and BTG conditions, respectively $(p>.05)$. The relationship between sets of variables specific to the WT condition was significant, Wilks' lamda $=.45, R_{c}^{2}=.55$, Approximate $F(15,94.26)=2.08, p<.05$. Based on the Cramer-Nicewander $(1979)$ index, approximately $22 \%$ of the overall variance associated with the set of dependent variables was explained by the predictor variables.

The first function was extracted and had a squared canonical correlation of $R_{c}^{2}=.42$, indicating that the two sets of variable shared approximately $42 \%$ of variance. Eigenvalues, percentages of variance explained, and squared canonical correlation for all functions are presented in Table 1.

Similar to factor analysis, determining what the latent functions represent can be ascertained by interpreting the structure coefficients associated with each variable (Shell \& Husman, 2008). Tables 2 and 3 display the structure coefficients for the dependent and predictor variables, respectively. The first predictor function is characterized by higher levels of Texture and lower levels of prior knowledge and Variability, although with a notably smaller contribution. The first dependent function is represented by lower levels of Text JOL, Graph JOL RCJ, COIS, and higher levels of Study Time. Taken together, the first function appears to indicate that reduced integrative behaviors between text and graphs, an overall longer page

\footnotetext{
${ }^{4}$ EOL data were excluded as participants had no foreknowledge of the different conditions and therefore this variable was not expected to vary as a function of condition.
} 
studying time, and lower confidence in comprehension is predicted by lower prior science knowledge, weaker beliefs in dynamic and open science knowledge (i.e., Variability), and stronger beliefs in unstructured and ambiguous science knowledge (i.e., Texture). To better understand this multivariate relation within the WT discrepancy condition, we conducted bivariate correlations. Although we calculated all possible correlations, we only interpret those correlations between EC and SRL within the WT condition as meaningful.

\subsubsection{Correlation Analyses}

Correlational analyses were conducted to determine if the relations between epistemic cognition and learning variables were along hypothesized directions (see section 1.4). Recall constructivist epistemic cognition was expected to negatively relate to judgments of comprehension and processing variables (Pieschl et al., 2008). Therefore, one-tailed probabilities were used to examine the relations between epistemic cognition and learning variables: metacognitive judgments, page studying times, and informational integration strategy-use (i.e., COIS) specific to each of the three discrepancy types. Descriptive and correlational statistics for variables specific to No Discrepancy pages are presented in Table 3; Table 4 relays correlational statistics for Within Text discrepancy pages; Table 5 contains correlational statistics for Between Text and Graph discrepancy pages. We discuss each in turn.

With few exceptions, across all three conditions, positive correlations were observed among metacognitive judgment variables, indicating that participants were consistent in their ratings of comprehension within each condition. Likewise, across the three experimental conditions, page study times positively related to COIS, signifying that participants were consistently spending more time on the pages they more frequently engaged in COIS as a learning strategy. On pages with discrepancies (i.e., WT and BTG), prior science knowledge was 
found to negatively relate to page study times, indicating that participants with greater knowledge of science spent less time on pages with discrepancies, regardless of their location in the multimedia content.

Within the WT discrepancy condition, in regard to relations between epistemic cognition and learning variables, Texture negatively related to three metacognitive judgment variables: Text JOL, Graph JOL, and RCJ. Thus, consistent with predications, individuals who believed that science knowledge was ambiguous and subjective consistently reported lower confidence that they had learned content. Further, again in the WT discrepancy condition, Variability negatively related to page processing time and the use of COIS. Thus, consistent with hypothesized relations, beliefs in dynamic and open science knowledge were related to shorter reading times and less frequent integration strategy-use compared to beliefs in static and closed knowledge.

We determined if correlation coefficients between epistemic cognition and learning variables were significantly different between conditions along expected directions. We thus used a procedure outlined by Lee and Preacher (2013) and Steiger (1980) to calculate differences between significant correlation coefficients across conditions. Constructivist epistemic cognition was expected to be more sensitive to discrepancies and thus more strongly negatively relate to learning variables (see section 1.4; Pieschl et al., 2008, 2014). Therefore, one-tailed probabilities were used to examine differences in coefficients between discrepancy conditions when there existed at least one significant correlation between a learning variable and an epistemic cognition variable. This resulted in ten comparisons between conditions (i.e., ND-WT and WT-BTG) of the relations between epistemic cognition and the following variables: Text JOL, Graph JOL, RCJ, Study Time, and COIS. 
The correlation between Texture and Text JOL (WT) was more negative than Text JOL without discrepancies (ND), $z=1.68, p<.05$. The correlation between Variability and page studying time for within text discrepancies was marginally more negative than the same relationship for no discrepancies, $z=1.62, p=.052$. No other comparisons were found to be significant.

\section{Discussion of Study 1}

Overall, findings from Study 1 are consistent with our hypotheses that constructivist epistemic cognition negatively relates to comprehension judgments and processing behaviors while learning and raise important questions about the role of epistemic cognition on selfregulated learning in particular contexts. In general, canonical correlations showed that a linear combination that formed the predictor variate consisting of more constructivist Texture beliefs, lower prior knowledge, and less constructivist Variability beliefs was significantly related to a dependent variate consisting of lower metacognitive judgments of comprehension, lower frequency of COIS, and longer page studying times. This relationship was observed for variables from Within-Text discrepancy condition and not the control (i.e., No Discrepancy) condition, which supports the view that constructivist epistemic cognition entails sensitivity to learning contexts and flexibility in adapting to contextual demands (Elen, Stahl, Bromme, \& Clarebout, 2011; Hammer \& Elby, 2002, 2003, 2010; Pieschl, Stahl, \& Bromme, 2013). Based on the standardized coefficient, it appears that Texture and prior knowledge make the largest and most meaningful contributions to the latent predictor variable that relates to an array of important cognitive and metacognitive self-regulated learning variables. To unpack and interpret this multivariate relationship, individual bivariate relations between WT condition variables are discussed below. 


\subsection{Texture Epistemic Beliefs and Processing Within-Text Discrepancies}

Stronger beliefs in unstructured, subjective, and ambiguous science knowledge (i.e., constructivist Texture beliefs) related to lower levels of self-evaluated comprehension. In the case of Text JOL, this relationship was stronger when studying pages with discrepancies embedded within the text compared to pages without discrepancies, suggesting that participants with stronger constructivist Texture beliefs were more sensitive to such discrepancies compared to their less constructivist counterparts. This finding is consistent with current hypotheses and previous research (Pieschl et al., 2008, 2014). JOL are known to have important implications for study time allocation, as the information gained from this metacognitive self-evaluation phase that is, if learning is proceeding well or not - is used to regulate subsequent behavior (Dunlosky \& Metcalfe, 2009; Metcalfe, 2002; Metcalfe \& Kornell, 2005). By virtue of being more sensitive to contextual conditions such as discrepancies, participants with constructivist epistemic Texture beliefs are better positioned to be more metacognitively aware and to be more adept at regulating their behaviors. Moreover, subjective self-evaluations of comprehension are one indication of learners' assessment of whether their learning is deviating from ideal levels of comprehension. Through showing that these metacognitive judgments covary with epistemic cognition, the current findings indirectly support theoretical models that claim epistemic cognition act as one set of inputs to learners' standards for learning and the consequences when these standards are not met (Bromme et al., 2010; Muis, 2007). Further, the current findings refined these theoretical models by adding a higher degree of specificity between metacognitive and epistemic constructs.

\subsection{Variability Epistemic Beliefs and Processing Within-Text Discrepancies}


Additionally, stronger beliefs in dynamic, open, and uncompleted science knowledge (i.e., constructivist Variability beliefs) related to lower frequency of integrating multimedia and less time spent studying content pages. With regard to time spent studying pages, the magnitude of the negative relationship between Variability and study time was larger for pages with WithinText discrepancies compared to those without discrepancies, suggesting that participants with stronger constructivist Variability beliefs were more sensitive to these discrepancies compared to their less constructivist counterparts. These findings are consistent with predictions and previous research showing that constructivist epistemic cognition relates to lower study allocation time for complex material (Pieschl et al., 2008). In particular, Pieschl et al. (2008) speculated that individuals with constructivist Variability beliefs spent less time studying hypermedia pages with detailed and complex content because they calibrated their study time allocation to the global task of learning as much as they could rather than calibrating to the local task of understanding a detailed page. Pieschl et al. noted that by differentiating between pages that would or would not contribute substantially to achieving the task of a global understanding, individuals with constructivist beliefs were more efficient with their study time. A novel contribution of the current study is to demonstrate that this effect, originally observed with complex content, is extended to content that contains discrepancies, and is observable by examining patterns of eye tracking.

\subsection{Relations between Epistemic Cognition, Metacognition, and Study Time Allocation}

This strategy for study time allocation is analogous to Metcalfe's (2002) region of proximal learning model, which states that learners will devote limited study time to content that is judged to be contributing most meaningfully to learning (i.e., a high rate of learning) and cease studying content that is judged not to be contributing meaningfully to learning (i.e., a low rate of 
learning) or stop when they feel that they are 'laboring in vain' (Metcalfe \& Kornell, 2005). We interpret the current findings under these theoretical models, and speculate that constructivist Variability beliefs inform an apprehension structure (Bromme et al., 2010) that allows individuals to be more sensitive to and identify cues from the content that indicate that it is not worth much of their time studying. In the case of the current study, with our use of unresolvable discrepancies, these individuals would be correct. Thus, we speculate that participants with constructivist Variability beliefs more readily recognized cues in Within-Text discrepancy pages that signaled that they could be more efficient with their study time if they quickly abandoned the current page they were viewing and proceeded onto new content. However, it should be noted that prior knowledge also negatively correlated with page studying times and canonical correlations revealed that prior knowledge contributed more meaningfully to the variate that related to page studying times. Thus, open questions remain on the relative roles of prior knowledge and epistemic cognition in the process of detecting cues of content quality and regulating subsequent learning.

Moreover, what remains unknown are what these cues are, whether participants actually notice the conceptual discrepancies in the current design, and the mechanisms that account for differences in patterns of eye tracking, study times, and metacognitive judgments observed in the current study. To identify the self-regulation processes that were undertaken in response to discrepancies and understand how and why correlational patterns emerged, further research was needed to triangulate current behavioral measures with verbal data channels, such as think-aloud protocols and retrospective interviews, which leading researchers have called for as important for the advancement of knowledge in these fields (Van Gog \& Jarodzka, 2013; Greene et al., 2010; Magliano \& Graesser, 1991). Thus, we undertook a second mixed method study with the 
objective to build off current insights to investigate these remaining questions (Creswell, 2014). Thus, our second research question that is addressed by Study 2 was: Given that learners regulate their cognitive and metacognitive strategies as a function of epistemic cognition, how and why does such adaptation occur?

\section{Study 2}

\subsection{Method}

\subsubsection{Participants}

Twenty undergraduate students were recruited from a large, public research university in North America $(N=20)$. Twelve self-reported as female $(60 \%)$ and eight as male; age ranged from 18 to 30 years $(M=21.4$ years) with an average self-reported GPA of 3.2/4.0 $(S D=0.6)$. Students were paid $\$ 30$ for their 3-hour participation.

\subsubsection{Materials and Procedure}

The materials and procedure for Study 2 replicated that of Study 1 with several additions. EC and SRL were examined with concurrent think-aloud protocols and retrospective interviews. Concurrent think-aloud protocols and retrospective interviews were supervised and conducted by the first author. Screen and audio recordings of these data were collected using Snagit ${ }^{\circledR}$ software $\left(\right.$ TechSmith $\left.^{\circledR}\right)$. More specifically, participants were instructed to think-aloud while studying the content pages (Ericson \& Simon, 1993) and were interviewed about their learning thoughts and behaviours immediately following completion of the learning session. Participants were instructed to read out loud and to vocalize everything that they were thinking and everything that they were doing while they studied the content. Prior to commencing, participants went through a brief think-aloud training session. During the concurrent think-aloud, participants were prompted to "keep talking" if they were silent for more than 3 seconds (Ericson \& Simon, 1993). 
During the retrospective interview, participants were asked about their learning behaviours during the experimental session, their thoughts and beliefs about factors that might affect these behaviours (e.g., prior knowledge), and whether they noticed conceptual discrepancies. Specifically, to avoid leading questions, the interviewer asked the following three questions in order: (1) "How would you judge the quality of the content?" (2) "Why or why not would you recommend its future use?" (3) "Did you encounter any errors or inaccuracies?"

\subsubsection{Data Analysis and Credibility}

\subsubsection{Given evidence from Study 1 that learners regulate their cognitive and metacognitive} strategies as a function of epistemic cognition, how and why does such adaptation occur?

Concurrent think-aloud protocols and retrospective interviews underwent qualitative thematic analysis (Creswell, 2007; Greene \& Yu, 2014; McCrudden \& Kendeou, 2014). We sought to gather insights into why discrepancies were or were not noticed and how they were resolved, which we considered to be processes of self-regulated learning. Further, we examined how epistemic cognition relates to these regulation processes of detection and resolution. We describe the process of this qualitative analysis in the following section.

To establish credibility in our analysis, we followed data analytic procedures described by Greene and Yu (2014), Creswell (2007), and Whittemore, Chase, and Mandle (2001). Concurrent think-aloud protocols and retrospective interviews were analyzed by the first author. The author watched screen recordings, listened to verbal reports for all participants in iterative cycles, and transcribed relevant segments. Relevant segments were identified and classified by low-inference indicators based on SRL and EC theories. Specifically, segments were transcribed if participants: (1) mentioned or engaged in behavior that reflected some aspect of the nature of knowledge or knowing (including aspects that reflected beliefs or cognitions about the simplicity 
or certainty of knowledge and the source and justification for knowing); or (2) mentioned or engaged in behavior that reflected awareness or control of cognitive, metacognitive, and/or motivational learning processes (including task definitions, standards or goals, enacted learning strategies, and evaluations). We adopted wide theoretical perspectives of SRL and EC to allow us to be open to new codes to emerge from the data not prefigured by current specific SRL or EC models.

We considered for analysis relevant segments that occurred either concurrently with the learning session or retrospectively in response to the interviewer's question. These data were then categorized into groups that shared common theoretical constructs mentioned above (e.g., beliefs about the source of knowledge). The first author iteratively returned to the original recordings to determine if additional data changed the boundaries of the codes. Once stability had been determined and no new meaningful codes appeared, transcription and coding ceased and overarching themes were inferred from the current set of codes (Creswell, 2007) ${ }^{5}$. To establish accuracy in our interpretation of the participants' meaning we present direct quotations from participants, triangulate our data, and present rich, thick descriptions where appropriate (Creswell, 2007; Whittemore, Chase, \& Mandle, 2001) ${ }^{6}$.

\subsection{Results and Discussion of Study 2}

\subsubsection{Qualitative Analysis}

4.2.1.1. Discrepancy detection. Overall, even after explicitly prompted to reflect on the quality and accuracy of the content, only eight participants (40\%) reported noticing inaccuracies, with some of those participants providing direct and unequivocal responses about the existence of inaccuracies and others providing qualified responses (see below). However, the majority of

\footnotetext{
${ }^{5}$ For details, see Creswell (2007, pp. 148-154).

${ }^{6}$ For details, see Creswell (2007, pp. 202-209).
} 
participants in this second study $(n=12 ; 60 \%)$ did not report noticing errors or inaccuracies in the content even after an explicit prompt to reflect on their potential existence. Beyond whether participants noticed discrepancies, we sought to explore why or why not discrepancies were detected, if detection occurred, how were they resolved, and if these regulation processes related to epistemic cognition.

Prior knowledge emerged as an important construct related to noticing discrepancies and regulation of resolution strategies. For those participants who reported not noticing discrepancies, many referred to their limited prior knowledge as a reason why they would not be able to do so. In response to being asked if they encountered any errors or inaccuracies, participants stated:

Participant Number 01 (PN01): I wouldn't be able to tell because I don't specialize.

PN17: Based on my prior knowledge of science which is pretty minimal I didn't [...] I don't think I would have caught them even if I was looking.

Further, beyond limited prior knowledge, participants also remarked on their capacity (or lack thereof) to evaluate science knowledge. Thus, we also interpreted that participants felt they lacked an epistemic self-efficacy or authority to question the science knowledge claims relayed in the content:

PN16: I know I'm not good in sciences, so I just followed what it said. 
We interpret these statements on prior knowledge and self-efficacy within theoretical frameworks of epistemic cognition (Greene, Azevedo, \& Torney-Putra, 2008; Hofer \& Pintrich, 1997; Muis, 2007). Specifically, we interpret these statements to be consistent with epistemic beliefs that the source and justification for knowing stems from external authority figures, like teachers or textbooks, in contrast to a belief that knowing stems from active personal construction using logic and evidence (Hofer \& Pintrich, 1997). As some participants had noted, the content in the current study could be interpreted as being "presented in an authoritative manner" (PN18) and thus reduced the likelihood that its claims were critically scrutinized by all participants. Relatedly, an epistemic belief in the infallibility of science knowledge was reported as another reason not to question content:

PN02: Science is kind of taken to be true [...] so I wasn't really looking for quality.

Taken together, low prior knowledge, low self-efficacy, and less constructivist epistemic beliefs are some potential mitigating factors that may account for the low rates of discrepancy detection observed in the current study (i.e., 40\%).

Indeed, other participants in this study who reported noticing discrepancies but who qualified their responses nonetheless echoed these themes. Despite clearly experiencing interruptions to learning, some participants would report having engaged in self-doubt over doubting the content. For example, when encountering a discrepancy in the content, one participant concurrently noted: 
PN12: I'll read this over again because I'm clearly not paying enough attention. Oh my god I'm so unfocused.

Later, this participant recall retrospectively:

PN12: I don't know if this is just me clearly not getting but there were sometimes when I thought the graph was wrong or had bad information, then I would get really confused and I would question my ability to think, so that would affect it. Then I guess if I found the topic more difficult, but if I had prior knowledge in a subject that would make it more easier.

Others who experienced interruptions to learning but stopped short of referring to them as flaws with the content likewise expressed episodes of self-doubt:

PN15: Reading new information kind of challenges [my prior knowledge] 'cause you're wondering like you start to doubt yourself.

Interviewer: Did you encounter any errors or inaccuracies?

PN18: I think I did, I'm constantly putting it back on myself because I'm not sure, but I think that some of the graphs were backwards, showed the reverse of what the text was saying.

Interviewer: Why would you put it back on yourself? 
PN18: If it was a test on [omitted] history, which I think I know really well, I would be like, no that's straight up wrong, and I would consider myself a better authority than that, but when it comes to science I just don't consider myself a better authority $[\ldots]$ it could be right but I don't see how it's right but I'm willing to believe there's an explanation that I just don't have.

PN08: I pretty much trusted it, which is funny because in my answer on the survey I was like, question everything! But then I really didn't question it, because I don't consider myself knowledgeable but although I guess there were a couple parts that were contradicted but that doesn't mean like there isn't a connection.

These participants reported experiencing interruptions or discrepancies, but attributed these shortcomings in comprehension to personal efforts or characteristics rather than definitively attributing interruptions to flaws in the content. The self-doubt or the lack of doubt of the content we inferred seems to be again in reference to the privileged epistemic status or authority of the experimental content over the self-perceived relative lack of expertise.

In contrast, other participants provided direct and unequivocal responses about the existence of discrepancies in the text.

PN04: Some of the contradictions seemed fairly obvious [...] it was more pronounced on the questions where I had like some prior knowledge, where I was like I definitely know this and it's definitely wrong. 
PN15: As I went through and saw more discrepancies I was more inclined to stick with my own intuition rather than the writing.

Overall, it became apparent that there was a strong relationship between prior knowledge, self-confidence, and unequivocal declaration of noticing discrepancies. Although we did not collect data on self-efficacy, to further substantiated a part of this relationship, we correlated prior knowledge test scores with dummy codes of whether or not participants explicitly reported noticing a conceptual discrepancy and found a large positive correlation, $r=.58, p<.01^{7}$. Thus, on the basis of triangulating our data, we conclude that noticing conceptual discrepancies in science content is related to prior knowledge. We further conclude on the basis of retrospective interviews that epistemic self-efficacy is likely also an active and influential construct worthy of future research.

4.2.1.2. Discrepancy resolution strategies. The themes described above - whether participants noticed discrepancies and how they interpreted their cause - are meaningful because they are intrinsically connected to the quality of resolution strategy that participants enacted. Indeed, when encountering discrepancies in the current study, participants initiated and regulated several diverse learning strategies. First, in reviewing screen and audio recordings of concurrent processing we did not observe any extraordinary pattern of resolution strategies for participants who did not report noticing discrepancies and for No Discrepancy content pages. For those who did express experiencing interruptions to their learning, participants enacted resolution strategies

\footnotetext{
${ }^{7}$ Similar analysis between explicit remarks of discrepancy detection and epistemic cognitive variables showed no significant correlations, $p>.5$. We interpret this non-significant result as indication that constructivist epistemic cognitive variables are not a sufficient condition to enable greater explicit detection, however, given the small sample analyzed $(n=20)$, more empirical research is needed to verify this claim. Further, this nonsignificant result does not rule out other possible responses to processing discrepancies beyond explicit verbal remarks of detection, including experiencing disequilibrium while learning.
} 
of various qualities. For example, some judged that the discrepant information is not relevant to achieving their goal to answer the question:

PN12: Wait that probably makes sense... whatever it's not relevant to the question [...] Ok just move on. I feel like I do understand and I don't understand.

PN12: If I thought the graphs didn't make sense I brought it back to the goal [to answer the question].

We interpret these and similar statements in accordance with self-regulated learning theory, and more specifically, as skilled SRL as it both demonstrates accurate judgments of content relevancy and goal-directed behaviour (Azevedo et al., 2012, 2013).

Given processing times, fixations, and integrations between multimedia representations, we also focused on how participants in this study reported regulating these behaviours in concurrent and retrospective records. After noticing discrepancies, some participants reported deciding to quickly navigate away from the content given the irreconcilable nature of the current discrepancies:

PN07: Once again I am just going to disregard this graph because it goes against everything that I've learned, let's see if I can find a direct quote in the text that contradicts the graph [...] The graph doesn't make any sense so I'm going to stop trying to think about that. 
PN18: A couple of them I went through faster because I felt like I got it, and a couple of them the graph made no sense and I was like, without new info there is only so long I'm going to spend on something I don't understand so it doesn't make sense so I'm going to move on.

These concurrent and retrospective reports may explain differences observed in processing times and fixations on content from Study 1. Specifically, when encountering a conceptual discrepancy and making the judgment that the discrepancy is logically irreconcilable with available resources, the most effective SRL strategy under those conditions would be to proceed to new content. Based on Study 1, participants who appeared to adopt this study time allocation strategy were those who reported the strongest constructivist Variability beliefs.

Further, although some individuals may report adopting the same strategy, they may differ in the efficiency with which they enact them. For example, when encountering the same conceptual discrepancy on the same page, both Participant \#11 and \#15 enacted COIS strategy in an attempt to resolve it. However, they differed in their efficiency in doing so:

PN11: [Inspecting graph] Oh, the number of protons shouldn't change, right? [...] Let me reread this... [scrolls to view text] where's the part about protons never being lost $[\ldots]$ "Notice when an ion is formed, the number of protons is unchanged." [scrolls to view graph] "Notice when an ion is formed, the number of protons is unchanged..." that doesn't match up [scrolls to view text] "Notice when an ion is formed, the number of protons is unchanged. It is the number of electrons that increases or decreases." [scrolls to view graph] So number of electrons, there, increases and decreases, so that seems to be 
consistent. Alright, so why [scrolls to view text] are the protons changing? Am I getting this wrong? [rereads text] skimming, skimming. Either I'm getting this wrong or the graph is incorrect. "Notice when an ion is formed, the number of protons is unchanged." [scrolls to view graph] Alright, hm. Perhaps I've got that wrong, but maybe not. [scrolls to view text] I'm pretty sure protons never change though. Pretty sure. Ok cool. [exits content page] [129 seconds]

PN15: [Inspecting graph] But the protons should stay the same [scrolls to view text] it says that somewhere over here... yeah "Notice when an ion is formed, the number of protons is unchanged" [scrolls to view graph] so that's a little strange. And here, the cation, the number of electrons, 12 , yeah the number of electrons would be 10 , and the protons should stay the same, so that's right. But the number of protons should be the same [scrolls to view text] throughout. So "why are ions called charged molecules?" [rereading question][exits content page][60 seconds]

Overall, Participant \#11 took more than twice as long to enact the same strategy and reach a similar conclusion as Participant \#15 (129 seconds vs. 60 seconds, respectively). This is possibly due to ineffective or redundant re-reading or coordinating of informational sources that may also have represented a low rate of learning (Metcalfe, 2002). In the context of an unresolvable discrepancy relayed in the above example, such additional efforts may represent what Metcalfe and Kornell (2005) refer to as 'laboring in vain,' which in Study 1 individuals with constructivist epistemic cognition were more sensitive to and more likely to avoid rather than persevering on pages with discrepancies embedded in the text. Notably, with reference to the Study 2 sample, 
PN11 scored approximately on the $25^{\text {th }}$ percentile of their constructivist Variability beliefs whereas PN15 scored approximately on the $90^{\text {th }}$ percentile on the same measure. Further, PN15 engaged in effective goal reinstantiation by focusing back onto the question for the page, further displaying skilled SRL. This example also supports Pieschl et al.'s (2008) contention that individuals with constructivist epistemic cognition are more sensitive to calibrate their efforts to the global learning task rather than individuals with less constructivist epistemic cognition who calibrate their efforts to the immediate and local learning contexts. We discuss this possibility and an integration of the findings from Studies 1 and 2 next.

\section{General Discussion}

The current studies sought to uncover specific empirical links between epistemic cognition and self-regulated learning within the context of processing conceptual discrepancies in a science multimedia environment. In brief, findings showed that individuals with constructivist epistemic cognition in science were more sensitive to adapting their cognitive and metacognitive learning processes in response to discrepancies in science texts, as evinced in finegrained analysis of eye tracking, computer log-files, and metacognitive judgments, and specifically towards the direction of allocating less studying time and lower judgments of learning, supporting Hypothesis 1. Additionally, detection of discrepancies was linked to the combined effects of prior science knowledge and epistemic self-efficacy. Qualitative analysis from Study 2 provided further insights into how and why quantitative findings from Study 1 were obtained. We address each point in turn and conclude with a discussion of the limitations of the study and directions for future research.

\subsection{Relations between Epistemic Cognition and Self-Regulated Learning}


Awareness and adaptation to external conditions are pillars of self-regulated learning (Azevedo et al., 2012, 2013; Greene, Hutchison, Costa, \& Crompton, 2012; Pieschl et al., 2012, 2013). This is especially important when processing inaccurate or discrepant knowledge claims, as misinformation on vital socio-scientific issues is increasingly becoming more prevalent online (Kata, 2012; Lewandowsky et al., 2012; Rapp \& Braasch, 2014) and the misconceptions this engenders remain formidable barriers to developing the public's understanding of science (Kahan, 2015; Sinatra et al., 2014). Thus, we explored how cognition about knowledge and knowing and self-regulated learning interacted within the context of detecting and resolving conceptual discrepancies in science multimedia.

For some time, researchers have proposed theoretical models that stipulate that constructivist epistemic cognition consistently yields more complex task definitions, more advanced learning standards and goals, use of deeper-level learning strategies, and more critical evaluations (Bromme et al., 2010; Greene et al., 2010; Muis, 2007). These predictions are gaining increasing evidentiary support by large-scale, primarily survey-based studies that have tested their validity (Chiu, Liang, \& Tsai, 2013; Franco et al., 2012; Muis et al., 2015). However, the current studies contribute to the growing trend of in-depth, fine-grained research that relays findings that complicate this relatively straightforward depiction of the relations between EC and SRL (Hammer \& Elby, 2002, 2003, 2010; Pieschl et al., 2008, 2014). With the addition of the second qualitative study, we were able to generate explanations for how and why quantitative patterns emerged and novel hypotheses that future research can address. Thus, the current findings refine and advance theories of EC and SRL and extend these frameworks to consider the increasingly important context of processing conceptual discrepancies. 
Specifically, on pages without discrepancies, we did not observe meaningful patterns of relations between epistemic cognition and SRL variables, in contrast to pages with discrepancies in the text. We surmised this difference reflected that individuals' epistemic cognition was not relevant or notably active while processing relatively straightforward expository science texts. However, when individuals in these studies encountered pages with text discrepancies, they expressed a range of reactions.

Participants with stronger constructivist Texture and Variability beliefs were more sensitive to such discrepancies compared to their less constructivist counterparts, and responded with lowered study time, fewer instances of coordination of informational sources, and lower judgments of learning, which are key variables in self-regulated learning (Dunlosky \& Metcalfe, 2009; Metcalfe, 2002; Metcalfe \& Kornell, 2005). By virtue of being more sensitive to contextual conditions such as discrepancies participants with constructivist epistemic cognition demonstrate higher levels of metacognitive awareness and control. These findings are both consistent with previous research and support theories that show relations between EC and SRL (Bromme et al., 2010; Muis, 2007; Pieschl et al., 2014).

Individuals who believed in vague and imprecise science knowledge did provide lower confidence of judgments of learning for texts that contained discrepancies compared to texts without discrepancies. This finding suggests that individuals were aware of increased processing difficulty associated with text discrepancies, and that individuals who believed in vague knowledge were especially sensitive to fluctuations in increased processing difficulty. Viewing knowledge as more complex is linked to perceiving tasks as more complex generally (Pieschl et al., 2013), yet the current findings demonstrate that beliefs about the Texture of knowledge also relate to calibrating post-task evaluations as well, which theoretically influences subsequent 
enactment of strategies in SRL models (Azevedo et al., 2012, 2013; Dunlosky \& Metcalfe, 2009; Winne \& Hadwin, 1998, 2008).

Further, individuals who believed in dynamic science knowledge responded differently to conceptual discrepancies by reading for a shorter time compared to their counterparts who believed in static science. Other items on the CAEB Variability factor - "completed," "irrefutable," "permanent" - indicate that a strong belief in static science knowledge may be associated with a belief that science represents enduring truths that have stood the test of time and are infallible. Presumably, such a belief would underprepare an individual to anticipate discrepancies in science texts and persist in trying to achieve resolution if they did, believing that they themselves were mistaken. Conversely, an individual who believed in temporary, refutable, and uncompleted science knowledge would be more likely to anticipate discrepancies, interpret them as such, and enact strategies appropriate to the situation, like proceeding on to new content. An analogous strategy of study time allocation was described in the region of proximal learning model by Metcalfe (2002). Based on the Study 1 findings, one possibility is that individuals with constructivist Variability beliefs more readily apprehended an unresolvable knowledge discrepancy and more efficiently allocated their time to achieve their overall learning goal.

Qualitative analyses from Study 2 showed that, except for a small subsample in the second study, most did not explicitly detect that an error had occurred. For those that did detect an error, they were dividedly equally between those who explicitly mentioned that the content contained a discrepancy and those that did not explicitly doubt the veracity of the content but who reported experiencing an interruption to their learning, similar to previous studies that sought to induce cognitive disequilibrium or confusion (D'Mello et al., 2014). A primary objective of the current studies was to determined if epistemic cognition distinguished these 
three subgroups and their range of responses to discrepancies. Based on our quantitative and qualitative analyses, what appeared to discriminate between these subgroups was their level of prior science knowledge and epistemic self-efficacy.

Individuals reported that their level of prior knowledge facilitated or constrained how quickly they could process and evaluate the content. One possibility is that existing knowledge schema allowed high prior knowledge students to engage in relatively quick knowledge verification behaviour. This entails checking incoming information against what is already known to evaluate its consistency and accuracy (Moos \& Azevedo, 2008) and potentially freeing up cognitive resources to devote to metacognitvely monitoring the quality of the content and comprehension difficulties (Hacker, 2014; Wang \& Chen, 2014). In contrast, lacking such schema, low prior knowledge students may have had to engage in relatively slower and more cognitively demanding knowledge construction behaviours.

Another possibility related to participants' epistemic self-efficacy with evaluating science texts, which appeared inextricably linked to their prior science knowledge. In our discussion, we use the term epistemic self-efficacy to refer to individuals' confidence in their ability to question the veracity of knowledge claims conveyed by external sources and themselves as the source of knowledge. This construct is therefore closely linked to theories that discuss individuals' beliefs about the source of knowledge (Belenky, Clinchy, Goldberger, \& Tarule. 1986; Chinn, Buckland, \& Samarapungavan, 2011). The finding that self-efficacy and prior knowledge are linked and relevant factors for learning is consistent with previous research that shows the confluence of confidence, self-efficacy, and prior knowledge function in parallel to influence subsequent achievement (Cordova, Sinatra, Jones, Taasoobshirazi, \& Lombardi, 2014). Beyond prior knowledge - which Hacker (2014) points to as one explanation for why individuals fail to 
detect textual problems - if epistemic self-efficacy were to function in tandem with constructivist Variability beliefs, such as acknowledging the tentativeness of science knowledge, then selfconfidence in one's ability to adjudicate between valuable and spurious knowledge may be heightened. The combination that results may lead to a strong stance with which to critically and efficiently assess the epistemic value of new content. However, overconfidence in epistemic selfefficacy may offer one account for the negative effects that stem from individuals relying on personal justification over expert knowledge (Bråten, Ferguson, Strømsø, \& Anmarkrud, 2013; Kahan, 2014). Overall, these findings provide specific evidence of how epistemic cognition interacts with learning conditions to relate to the enactment phase of SRL.

In sum, the current studies found specific relations between epistemic cognition and selfregulated learning as individuals studied science multimedia with knowledge discrepancies. Specifically, using a multi-study, mixed method design, we obtained evidence that epistemic cognition relates to behavioural measures of self-regulated learning, evinced in eye tracking, study times, and metacognitive judgments, in the context of processing conceptual discrepancies within texts. Taken together, the two studies reported are among the first to provide empirical evidence for relations between epistemic cognition and specific phases and components of selfregulated learning at a fine-grained and process level of analysis. Overall, we found several important findings: a belief in variable science knowledge related to lower text processing times and lower enactment of coordinating multiple media; a belief in subjective and ambiguous science knowledge related to lower confidence judgments of learning; and prior knowledge and epistemic self-efficacy in a specific domain emerged as important themes for detection of discrepancies and enactment of resolution strategies.

\subsection{Unique Contributions of the Current Studies}


Findings from the current studies present unique theoretical and methodological contributions. In particular, with our use of fine-grained measures of self-regulated learning we were able to show how theories of the relations between EC and SRL could be refined by specific phases (e.g., enactment) and components (Retrospective Confidence Judgments). Additionally, from qualitative analysis we were able to discern other active and relevant constructs, like epistemic self-efficacy, heretofore not yet directly investigated. Further, we extend theoretical frameworks of EC and SRL to the increasingly important context of processing conceptual discrepancies. In this effort, we respond to calls to assess the functioning of EC with research that adopts a "double track" approach (Bromme et al., 2010) that reflects its fine-grained, contextualized nature (Hammer \& Elby, 2002, 2010). Specifically, this approach pairs an analysis of EC and related learning processes with an analysis of the nature learning content to ascertain how well individuals adapt the former to suit the latter (Bromme et al., 2010). In so doing, researchers obtain a clearer picture of how EC might affect SRL adaptation. In terms of methodology, we were able to extract and triangulate fine-grained analysis from eye tracking data, computer log-files, metacognitive judgments, and concurrent and retrospective verbal reports to inform our conclusions about relations between EC and SRL.

\subsection{Limitations and Future Directions}

The conclusions of the current studies are limited in several ways. First, the small sample sizes limit statistical power and generalizability of the findings. Therefore, caution is recommended when interpreting the results. Second, the psychological responses to the current conceptual discrepancies may not encompass all possible reactions to discrepant knowledge. Beyond conflicts relayed within a single source, other discrepancies include conflicts between multiple sources (Bråten, Anmarkrud, Brandmo, \& Strømsø, 2014) and conflicts between source 
and individual knowledge, most clearly exemplified in refutational texts (Kendeou, Smith, \& O’Brien, 2013; Kendeou, Walsh, Smith, \& O’Brien, 2014). Despite this potential limitation, we note that experimentally inducing interruptions to learning is a common and useful research paradigm (e.g., D’Mello et al., 2014; Hacker, 2014) to study how individuals initiate and regulate important resolution strategies, which are valuable to investigate in their own right. Further, as individuals gain access to online content that is increasingly authored by non-refereed sources, encountering discrepancies may become more prevalent.

Future research should test the utility of epistemic self-efficacy as an active and influential construct for learning about controversial socio-scientific issues, such as climate change and vaccinations. Further, precisely delineating the pattern of epistemic cognition and self-regulated learning that are adaptive in which context is needed to design effective interventions (Bromme et al., 2010). Educationally, the current findings highlight the importance of epistemic cognition on quality learning and provide variables of self-regulated learning for interventions to target and measure as metrics for success (e.g., confidence to question content, vigilance in detecting discrepancies, coordinating informational sources to resolve them) to support the development of $21^{\text {st }}$ century literacies. However, future work should examine how the current body of empirical findings can be fruitfully applied to other naturalistic environments. 


\section{References}

Azevedo, R. (2014). Metacognition and multimedia learning. In R. E. Mayer (Ed.), Cambridge handbook of multimedia ( $2^{\text {nd }}$ ed., pp. 647-672). Cambridge, England: Cambridge University Press.

Azevedo, R. (2015). Defining and measuring engagement and learning in science: Conceptual, theoretical, methodological, and analytical issues. Educational Psychologist, 50(1), 8494.

Azevedo, R., Feyzi-Behnagh, R., Duffy, M., Harley, J., \& Trevors, G. (2012). Metacognition and self-regulated learning in student-centered learning environments. In D. Jonassen and S. Land (Eds), Theoretical foundations of learning environments. NY: Routledge.

Azevedo, R., Harley, J., Trevors, G., Duffy, M., Feyzi-Behnagh, R., Bouchet, F., \& Landis, R. S. (2013). Using trace data to examine the complex roles of cognitive, metacognitive, and emotional self-regulatory processes during learning with multi-agents systems. In R. Azevedo \& V. Aleven (Eds.). International handbook of metacognition and learning technologies (pp. 427-449). Amsterdam: Springer.

Azevedo, R., Moos, D., Johnson, A., \& Chauncey, A. (2010). Measuring cognitive and metacognitive regulatory processes used during hypermedia learning: Issues and challenges. Educational Psychologist, 45, 210-223.

Bannert, M., \& Mengelkamp, C. (2013). Scaffolding through metacognitive prompts. In R. Azevedo \& V. Aleven (Eds.), International handbook of metacognition and learning technologies (pp. 171-186). Amsterdam: Springer.

Barzilai, S., \& Zohar, A. (2012). Epistemic thinking in action: Evaluating and integrating online sources. Cognition and Instruction, 30, 39-85, doi:10.1080/07370008.2011.636495 
Barzilai, S., \& Zohar, A. (2014). Reconsidering personal epistemology as metacognition: A multifaceted approach to the analysis of epistemic thinking. Educational Psychologist, 49, 13-35, doi:10.1080/00461520.2013.863265

Bouchet, F., Harley, J., Trevors, G., \& Azevedo, R. (2013). Clustering and profiling students according to their interactions with an intelligent tutoring system fostering self-regulated learning. Journal of Educational Data Mining, 5, 104-146.

Braasch, J. L., Rouet, J., Vibert, N., \& Britt, M. A. (2012). Readers' use of source information in text comprehension. Memory and Cognition, 40, 450-465.

Bråten, I., Anmarkrud, Ø., Brandmo, C., \& Strømsø, H.I. (2014). Developing and testing a model of direct and indirect relationships between individual differences, processing, and multiple-text comprehension. Learning and Instruction, 30, 9-24.

Bråten, I., Ferguson, L.E., Strømsø, H.I., \& Anmarkrud, Ø. (2014). Student working with multiple conflicting documents on a science issue: Relations between epistemic cognition while reading and sourcing and argumentation in essays. British Journal of Educational Psychology, 84, 58-85.

Bromme, R., Pieschl, S., \& Stahl, E. (2010). Epistemological beliefs are standards for adaptive learning: A functional theory about epistemological beliefs and metacognition. Metacognition and Learning, 5, 7-26.

Burkett, C., \& Azevedo, R. (2012). The effect of multimedia discrepancies on metacognitive judgments. Computers and Human Behavior, 28, 1276-1285.

Chinn, C. A., \& Brewer, W. F. (1993). The role of anomalous data in knowledge acquisition: A theoretical framework and implications for science instruction. Review of Educational Research, 63, 1-49. 
Chiu, Y.-L., \& Liang, J.-C., \& Tsai, C.-C. (2013). Internet-specific epistemic beliefs and selfregulated learning in online academic information searching. Metacognition and Learning 8, 235-260, doi:10.1007/s11409-013-9103-x

Cordova, J.R., Sinatra, G.M., Jones, S.H., Taasoobshirazi, G., \& Lombardi, D. (2014). Confidence in prior knowledge, self-efficacy, interest and prior knowledge: Influences on conceptual change. Contemporary Educational Psychology, 39, 164-174.

Creswell, J.W. (2014). Research design: Qualitative, quantitative and mixed methods approaches. 4th Edition. California: Thousand Oaks.

D’Mello, S. K., \& Graesser, A. C. (2014). Confusion and its dynamics during device comprehension with breakdown scenarios. Acta Psychologica, 151, 106-116.

D'Mello, S. K., Lehman, B. Pekrun, R., \& Graesser, A. C. (2014). Confusion can be beneficial for learning. Learning \& Instruction, 29, 153-170.

Dunlosky, J., \& Metcalfe, J. (2009). Metacognition: A textbook for cognitive, educational, life span and applied psychology. Newbury Park, CA: Sage.

Elen, J., Stahl, E., Bromme, R., \& Clarebout, G. (2011) (Eds.). Links between beliefs and cognitive flexibility: Lessons learned. New York: Springer.

Ericsson, A. K., \& Simon, H. A. (1993). Protocol analysis: Verbal reports as data (Rev. ed.). Cambridge, MA: MIT Press.

Farrell, J. (2015). Corporate funding and ideological polarization about climate change. Proceedings of the National Academy of Sciences. doi:10.1073/pnas.1509433112

Ferguson, L. E., Bråten, I., \& Strømsø, H. I. (2012). Epistemic cognition when students read multiple documents containing conflicting scientific evidence: A think-aloud study. Learning and Instruction, 22, 103-120. doi:10.1016/j.learninstruc.2011.08.002 
Feyzi-Behnagh, R., Azevedo, R., Legowski, E., Reitmeyer, K., Tseytlin, E., \& Crowley, R. (2014). Metacognitive scaffolds improve self-judgments of accuracy in a medical intelligent tutoring system. Instructional Science, 42, 159-181.

Franco, G. M., Muis, K. R., Kendeou, P., Wang, X., Ranellucci, J., \& Sampasivam, L. (2012). Examining the influences of epistemic beliefs and knowledge representations on cognitive processing and conceptual change when learning physics. Learning and Instruction, 22, 62-77, doi:10.1016/j.learninstruc.2011.06.003

Graesser, A., Lu, S., Olde, B., Cooper-Pye, E., \& Whitten, S. (2005). Question asking and eye tracking during cognitive disequilibrium: comprehending illustrated texts on devices when the devices break down. Memory and Cognition, 33, 1235-1247. doi:10.3758/BF03193225.

Greene, J. A., \& Azevedo, R. (2009). A macro-level analysis of SRL processes and their relations to the acquisition of sophisticated mental models. Contemporary Educational Psychology, 34, 18-29.

Greene, J. A., Azevedo, R., \& Torney-Purta, J. (2008). Modeling epistemic and ontological cognition: Philosophical perspectives and methodological directions. Educational Psychologist, 43, 142-160.

Greene, J. A., Hutchison, L. A., Costa, L., \& Crompton, H. (2012). Investigating how college students' task definitions and plans relate to self-regulated learning processing and understanding of a complex science topic. Contemporary Educational Psychology, 37, 307-230.

Greene, J. A., Moos, D. C. and Azevedo, R. (2011). Self-regulation of learning with computerbased learning environments. New Directions for Teaching and Learning, 126, 107-115. 
Greene, J. A., Muis, K. R., \& Pieschl, S. (2010). The role of epistemic beliefs in students' selfregulated learning with computer-based learning environments: Conceptual and methodological issues. Educational Psychologist, 45, 245-257, doi:10.1080/00461520.2010.515932

Greene, J. A., \& Yu, S. B. (2014). Modeling and measuring epistemic cognition: A qualitative re-investigation. Contemporary Educational Psychologist, 39, 12-28, doi:10.1016/j.cedpsych.2013.10.002

Greene, J. A., Yu, S. B., Copeland, D. Z. (2014). Measuring critical components of digital literacy and their relationships with learning. Computers \& Education, 76, 55-69, doi:10.1016/j.compedu.2014.03.008

Hacker, D. J. (2014). Failures to detect textual problems during reading. In D. N. Rapp \& J. L. G. Braasch (Eds.) Processing inaccurate information: Theoretical and applied perspectives from cognitive science and the educational sciences (pp. 73-92). Cambridge, MA: MIT Press.

Hammer, D. H., \& Elby, A. (2002). On the form of personal epistemology. In B. K. Hofer \& P.R. Pintrich (Eds.), Personal epistemology: The psychology of beliefs about knowledge and knowing (pp. 169-190). Mahwah, NJ: Erlbaum.

Hammer, D., \& Elby, A. (2003). Tapping epistemological resources for learning physics. Journal of the Learning Sciences, 12, 53-90.

Hofer, B. K., \& Pintrich, P. R. (1997). The development of epistemological theories: Beliefs about knowledge and knowing and their relation to learning. Review of Educational Research, 67, 88-140, doi:10.3102/00346543067001088 
Hsu, C.-Y., Tsai, M.-J., Hou, H. T., \& Tsai, C.-C. (2014). Epistemic beliefs, online search strategies and behavioral patterns while exploring socioscientific issues. Journal of Science Education and Technology, 23, 471-480.

Kammerer, Y., Bråten, I., Gerjets, P., \& Strømsø, H. I. (2013). The role of Internet-specific epistemic beliefs in laypersons' source evaluations and decisions during Web search on a medical issue. Computers in Human Behavior, 29, 1193-1203, doi:10.1016/j.chb.2012.10.012

Kammerer, Y., \& Gerjets, P. (2012). Effects of search interface and Internet-specific epistemic beliefs on source evaluations during Web search for medical information: an eye-tracking study. Behaviour \& Information Technology, 31, 83-97, doi:10.1080/0144929X.2011.599040

Kata, A. (2012). Anti-vaccine activists, Web 2.0, and the postmodern paradigm - An overview of tactics and tropes used online by the anti-vaccination movement. Vaccine, 30, 37783789, doi:10.1016/j.vaccine.2011.11.112

Kendeou, P., Smith, E. R., \& O’Brien, E.J. (2013). Updating during reading comprehension: Why causality matters. Journal of Experimental Psychology: Learning, Memory, \& Cognition, 39, 854-865. doi: 10.1037/a0029468

Kendeou, P., Walsh, E., Smith, E. R., \& O'Brien, E. J. (2014). Knowledge revision processes in refutation texts. Discourse Processes, 51, 374-397. doi:10.1080/0163853X.2014.913961

Kinnunen, R., \& Vauras, M. (1995). Comprehension monitoring and the level of comprehension in high- and low-achieving primary school children's reading. Learning and Instruction, $5,143-165$. 
Lee, W.-C., Chiu, Y.-L., Liang, J.-C., \& Tsai, C.-C. (2014). Exploring the structural relationships between high school students' Internet-specific epistemic beliefs and their utilization of online academic help seeking. Computers in Human Behavior, 36, 391-400, doi:10.1016/j.chb.2014.03.069

Lewandowsky, S.; Ecker, U. K. H.; Seifert, C.; Schwarz, N. \& Cook, J. (2012). Misinformation and its correction: Continued influence and successful debiasing. Psychological Science in the Public Interest, 13, 106-131. doi: 10.1177/1529100612451018

Magliano, J. P., \& Graesser, A. C. (1991). A three-pronged method for studying inference generation in literary text. Poetics, 20, 193-232.

Mandler, G. (1984). Mind and body: Psychology of emotion and stress. New York: W.W. Norton \& Company.

Mandler, G. (1990). Interruption (discrepancy) theory: review and extensions. In S. Fisher, \& C. L. Cooper (Eds.), On the move: The psychology of change and transition (pp. 13e32). Chichester: Wiley.

Moos, D. C., \& Azevedo, R. (2008). Self-regulated learning with hypermedia: The role of prior domain knowledge. Contemporary Educational Psychology, 33, 270-298.

Muis, K. R. (2007). The role of epistemic beliefs in self-regulated learning. Educational Psychologist, 42, 173-190.

Muis, K. R., \& Franco, G. (2009). Epistemic beliefs: Setting the standards in self-regulated learning. Contemporary Educational Psychology, 34, 306-318, doi:10.1016/j.cedpsych.2009.06.005

Muis, K., Pekrun, R., Azevedo, R., Sinatra, G., Trevors, G., Meier, E., \& Heddy, B. (2015). The curious case of climate change: Epistemic emotions mediate relations between epistemic 
beliefs, learning strategies and learning outcomes. Learning and Instruction, 39, 168-183, doi:10.1016/j.learninstruc.2015.06.003

Opfermann, M., Scheiter, K., Gerjets, P., \& Schmeck, A. (2013). Hypermedia and selfregulation: An interplay in both directions. In R. Azevedo \& V. Aleven (Eds.), International handbook of metacognition and learning technologies (pp. 129-141). Amsterdam: Springer.

Piaget, J.-P. (1952). The origins of intelligence in children. International Universities Press, New York.

Pieschl, S., Stahl, E., \& Bromme, R. (2008). Epistemological beliefs and self-regulated learning with hypertext. Metacognition and Learning, 3, 17-37, doi:10.1007/s11409-007-9008-7

Pieschl, S., Stahl, E., \& Bromme, R. (2013). Adaptation to context as core component of selfregulated learning: The example of complexity and epistemic beliefs. In R. Azevedo \& V. Aleven (Eds.), International handbook of metacognition and learning technologies (pp. 53-65). Springer New York.

Pieschl, S., Stallmann, F., \& Bromme, R. (2014). High school students' adaptation of task definitions, goals and plans to task complexity: The impact of epistemic beliefs. Psychological Topics, 23, 31-52.

Pintrich, P.R. (2000). The role of goal orientation in self -regulated learning. In M. Boekaerts, P.R. Pintrich, \& M. Zeidner (Eds.), Handbook of Self-regulation (pp. 452-502).San Diego: Academic Press

Rapp, D. N., \& Braasch, J. L. G. (2014) (Eds.) Processing inaccurate information: Theoretical and applied perspectives from cognitive science and the educational sciences. Cambridge, MA: MIT Press. 
Rapp, D. N. \& Kendeou, P. (2007). Revising what readers know: Updating text representations during narrative comprehension. Memory and Cognition, 35, 2019-2032. doi:10.3758/BF03192934

Rapp, D. N. \& Kendeou, P. (2009). Noticing and revising discrepancies as texts unfold. Discourse Processes, 46, 1-24. doi:10.1080/01638530802629141

Sinatra, G. M., Kienhues, D. \& Hofer, B. (2014). Addressing challenges to public understanding of science: Epistemic cognition, motivated reasoning, and conceptual change. Educational Psychologist. doi:10.1080/00461520.2014.916216

Stahl, E., \& Bromme, R. (2007). The CAEB: An instrument for measuring connotative aspects of epistemological beliefs. Learning and Instruction, 17, 773-785.

Strømsø, H. I., \& Bråten, I. (2010). The role of personal epistemology in the self-regulation of Internet-based learning. Metacognition and Learning, 5, 91-111, doi:10.1007/s11409009-9043-7

Trevors, G., \& Muis, K. (2015). Effects of text structure, reading goals, and epistemic beliefs on conceptual change. Journal of Research in Reading, 38, 361-386. doi:10.1111/14679817.12031

Trevors, G., Duffy, M., \& Azevedo, R. (2014). Note-taking within MetaTutor: Interactions between an intelligent tutoring system and prior knowledge on note-taking and learning. Educational Technology Research \& Development, 62, 507-528. doi:10.1007/s11423014-9343-8

van Gog, T., \& Jarodzka, H. (2013). Eye tracking as a tool to study and enhance cognitive and metacognitive processes in computer-based learning environments. In R. Azevedo \& V. 
Aleven (Eds.), International handbook of metacognition and learning technologies (pp. 143-156). Amsterdam: Springer.

Wang, J.-R., \& Chen, S.-F. (2014). Exploring mediating effect of metacognitive awareness on comprehension of science texts through structural equation modeling analysis. Journal of Research in Science Teaching, 51, 175-191.

Winne, P. H., \& Hadwin, A. (2008). The weave of motivation and self-regulated learning. In D. Schunk \& B. Zimmerman (Eds.), Motivation and self-regulated learning: Theory, research and applications (pp. 297-314).

Winne, P. H., \& Hadwin, A.F. (1998). Studying as self-regulated learning. In D.J. Hacker, J. Dunlosky, \& A. Graesser (Eds.), Metacognition in educational theory and practice (pp. 277-304). Hillsdale, NJ: Erlbaum.

Winograd, P., \& Johnson, P. (1982). Comprehension monitoring and the error detection paradigm. Journal of Reading Behavior, 14, 61-76.

Zohar, A., \& Barzilai, S. (2013). A review of research on metacognition in science education: Current and future directions. Studies in Science Education, 49, 121-169, doi:10.1080/03057267.2013.847261 
Table 1

Eigenvalues, Cumulative Percentage of Explained Variance, and Squared Canonical Correlations for each Canonical Function.

\begin{tabular}{cccc}
\hline Function & Eigenvalue & $\begin{array}{c}\text { Percent Variance } \\
\text { Explained }\end{array}$ & $\begin{array}{c}\text { Squared Canonical } \\
\text { Correlation }\end{array}$ \\
\hline $\mathbf{1}$ & $\mathbf{. 7 4}$ & $\mathbf{7 4 . 5 2}$ & $\mathbf{. 4 2}$ \\
2 & .17 & 17.39 & .15 \\
3 & .08 & 8.09 & .07 \\
\hline
\end{tabular}


Table 2

Structure Coefficients for the First Predictor Canonical Variate.

\begin{tabular}{lc}
\hline Predictor Variable & Function 1 \\
\hline Prior Knowledge & -.62 \\
Variability & -.07 \\
Texture & .82 \\
\hline
\end{tabular}

Table 3

Structure Coefficients for the First Dependent Canonical Variate.

\begin{tabular}{lc}
\hline Dependent Variable & Function 1 \\
\hline JOL_T & -.50 \\
JOL_G & -.52 \\
RCJ & -.59 \\
COIS & -.47 \\
PAGE TIME & .31 \\
\hline
\end{tabular}


Table 4

Descriptive and correlation statistics between epistemic cognition and metacognitive judgments, page studying times, and eye-gaze pattern on No Discrepancy pages.

\begin{tabular}{|c|c|c|c|c|c|c|c|c|c|}
\hline & 1 & 2 & 3 & 4 & 5 & 6 & 7 & 8 & 9 \\
\hline 1. Variability ${ }^{a}$ & $\begin{array}{l}4.71 \\
(.89)\end{array}$ & .14 & .28 & -.03 & .11 & .02 & .06 & -.09 & -.16 \\
\hline 2. Texture ${ }^{a}$ & & $\begin{array}{l}2.74 \\
(.63)\end{array}$ & -.06 & .04 & -.19 & $-.42 * *$ & -.26 & .17 & -.16 \\
\hline 3. Prior Knowledge ${ }^{b}$ & & & $\begin{array}{c}.46 \\
(.14)\end{array}$ & .01 & .23 & .11 & .10 & -.21 & .20 \\
\hline 4. $\mathrm{EOL}^{\mathrm{c}}$ & & & & $\begin{array}{c}63.93 \\
(16.62)\end{array}$ & $.52 * *$ & .19 & $.40 * *$ & .13 & .02 \\
\hline 5. DJOL text ${ }^{c}$ & & & & & $\begin{array}{c}74.41 \\
(15.34)\end{array}$ & $.56^{* *}$ & $.74 * *$ & .01 & $.31 *$ \\
\hline 6. DJOL graph ${ }^{\mathrm{c}}$ & & & & & & $\begin{array}{c}79.05 \\
(15.82)\end{array}$ & $.63 * *$ & -.14 & -.04 \\
\hline 7. $\mathrm{RCJ}^{\mathrm{c}}$ & & & & & & & $\begin{array}{c}71.55 \\
(15.64)\end{array}$ & .11 & .18 \\
\hline 8. Study Time ${ }^{d}$ & & & & & & & & $\begin{array}{l}138.71 \\
(51.49)\end{array}$ & $.40 * *$ \\
\hline 9. $\mathrm{COIS}^{\mathrm{e}}$ & & & & & & & & & $\begin{array}{l}2.99 \\
(.81) \\
\end{array}$ \\
\hline
\end{tabular}

Note. Variables represent data specific to No Discrepancy pages; Means and standard deviations displayed on the diagonal; Significance of Variability and Texture coefficients estimated with one-tailed probability; EOL = Ease of Learning; DJOL = Delayed Judgment of Learning; RCJ = Retrospective Confidence Judgment; Study Time $=$ Average Study Duration; COIS $=$ Coordinating Informational Sources.

$* p<.05 . * * p<.01$.

a $0-7$ Likert scale

${ }^{\mathrm{b}}$ proportion correct

${ }^{\mathrm{c}} 0$-100 Likert scale

d in seconds

${ }^{\mathrm{e}}$ frequency count, square-root transformation 
Table 5

Descriptive and correlation statistics between epistemic cognition and metacognitive judgments, page studying times, and eye-gaze pattern on Within-Text discrepancy pages.

\begin{tabular}{|c|c|c|c|c|c|c|c|c|c|}
\hline & 1 & 2 & 3 & 4 & 5 & 6 & 7 & 8 & 9 \\
\hline 1. Variability ${ }^{a}$ & $\begin{array}{l}4.71 \\
(.89)\end{array}$ & .14 & .28 & .02 & -.01 & .06 & .04 & $-.32 *$ & $-.28^{*}$ \\
\hline 2. Texture ${ }^{a}$ & & $\begin{array}{l}2.74 \\
(.63)\end{array}$ & -.06 & -.08 & $-.38 * *$ & $-.36^{* *}$ & $-.42 * *$ & .03 & $-.29 *$ \\
\hline 3. Prior Knowledge ${ }^{b}$ & & & $\begin{array}{c}.46 \\
(.14)\end{array}$ & .15 & .05 & .09 & .09 & $-.30^{*}$ & .14 \\
\hline 4. $\mathrm{EOL}^{\mathrm{c}}$ & & & & $\begin{array}{c}66.55 \\
(18.10)\end{array}$ & $.39^{* *}$ & $.46^{* *}$ & $.54 * *$ & .17 & .08 \\
\hline 5. DJOL text ${ }^{c}$ & & & & & $\begin{array}{c}73.10 \\
(13.57)\end{array}$ & $.73 * *$ & $.73^{* *}$ & .14 & .12 \\
\hline 6. DJOL graph ${ }^{\mathrm{c}}$ & & & & & & $\begin{array}{c}80.83 \\
(14.77)\end{array}$ & $.64 * *$ & .17 & .18 \\
\hline 7. $\mathrm{RCJ}^{\mathrm{c}}$ & & & & & & & $\begin{array}{c}75.60 \\
(14.32)\end{array}$ & .05 & -.01 \\
\hline 8. Study Time ${ }^{d}$ & & & & & & & & $\begin{array}{l}131.02 \\
(47.59)\end{array}$ & $.49^{* *}$ \\
\hline 9. COIS $^{\mathrm{e}}$ & & & & & & & & & $\begin{array}{c}3.49 \\
(1.08)\end{array}$ \\
\hline
\end{tabular}

Note. Variables represent data specific to Within-Text discrepancy pages; Means and standard deviations displayed on the diagonal; Significance of Variability and Texture coefficients estimated with one-tailed probability; EOL = Ease of Learning; DJOL = Delayed Judgment of Learning; RCJ = Retrospective Confidence Judgment; Study Time $=$ Average Study Duration; COIS $=$ Coordinating Informational Sources .

$* p<.05 . * * p<.01$.

${ }^{\text {a }} 0-7$ Likert scale

${ }^{\mathrm{b}}$ proportion correct

c 0-100 Likert scale

${ }^{d}$ in seconds

${ }^{\mathrm{e}}$ frequency count, square-root transformation 
Table 6

Descriptive and correlation statistics between epistemic cognition and metacognitive judgments, page studying times, and eye-gaze pattern on Between Text and Graph discrepancy pages.

\begin{tabular}{|c|c|c|c|c|c|c|c|c|c|}
\hline & 1 & 2 & 3 & 4 & 5 & 6 & 7 & 8 & 9 \\
\hline 1. Variability ${ }^{a}$ & $\begin{array}{l}4.71 \\
(.89)\end{array}$ & .14 & .28 & -.18 & .07 & -.19 & .10 & -.23 & -.20 \\
\hline 2. Texture ${ }^{a}$ & & $\begin{array}{l}2.74 \\
(.63)\end{array}$ & -.06 & -.05 & -.21 & -.18 & $-.26^{*}$ & .06 & -.20 \\
\hline 3. Prior Knowledge ${ }^{b}$ & & & $\begin{array}{c}.46 \\
(.14)\end{array}$ & .01 & .30 & -.08 & $.41^{* *}$ & $-.31 *$ & .08 \\
\hline 4. $\mathrm{EOL}^{\mathrm{c}}$ & & & & $\begin{array}{c}60.60 \\
(14.95)\end{array}$ & $.46^{* *}$ & .09 & $.48 * *$ & .18 & .01 \\
\hline 5. DJOL text ${ }^{c}$ & & & & & $\begin{array}{c}77.86 \\
(13.26)\end{array}$ & .10 & $.75^{* *}$ & .03 & -.13 \\
\hline 6. DJOL graph ${ }^{\mathrm{c}}$ & & & & & & $\begin{array}{c}60.24 \\
(15.89)\end{array}$ & -.02 & -.11 & -.14 \\
\hline 7. $\mathrm{RCJ}^{\mathrm{c}}$ & & & & & & & $\begin{array}{c}73.81 \\
(18.86)\end{array}$ & -.05 & -.07 \\
\hline 8. Study Time ${ }^{d}$ & & & & & & & & $\begin{array}{l}140.21 \\
(53.26)\end{array}$ & $.32 *$ \\
\hline 9. COIS $^{\mathrm{e}}$ & & & & & & & & & $\begin{array}{c}2.87 \\
(1.02)\end{array}$ \\
\hline
\end{tabular}

Note. Variables represent data specific to Between Text and Graph discrepancy pages; Means and standard deviations displayed on the diagonal; Significance of Variability and Texture coefficients estimated with onetailed probability; EOL = Ease of Learning; DJOL = Delayed Judgment of Learning; RCJ = Retrospective Confidence Judgment; Study Time = Average Study Duration; COIS = Coordinating Informational Sources . $* p<.05 . * * p<.01$.

a $0-7$ Likert scale

${ }^{\mathrm{b}}$ proportion correct

c 0-100 Likert scale

${ }^{d}$ in seconds

${ }^{\mathrm{e}}$ frequency count, square-root transformation 


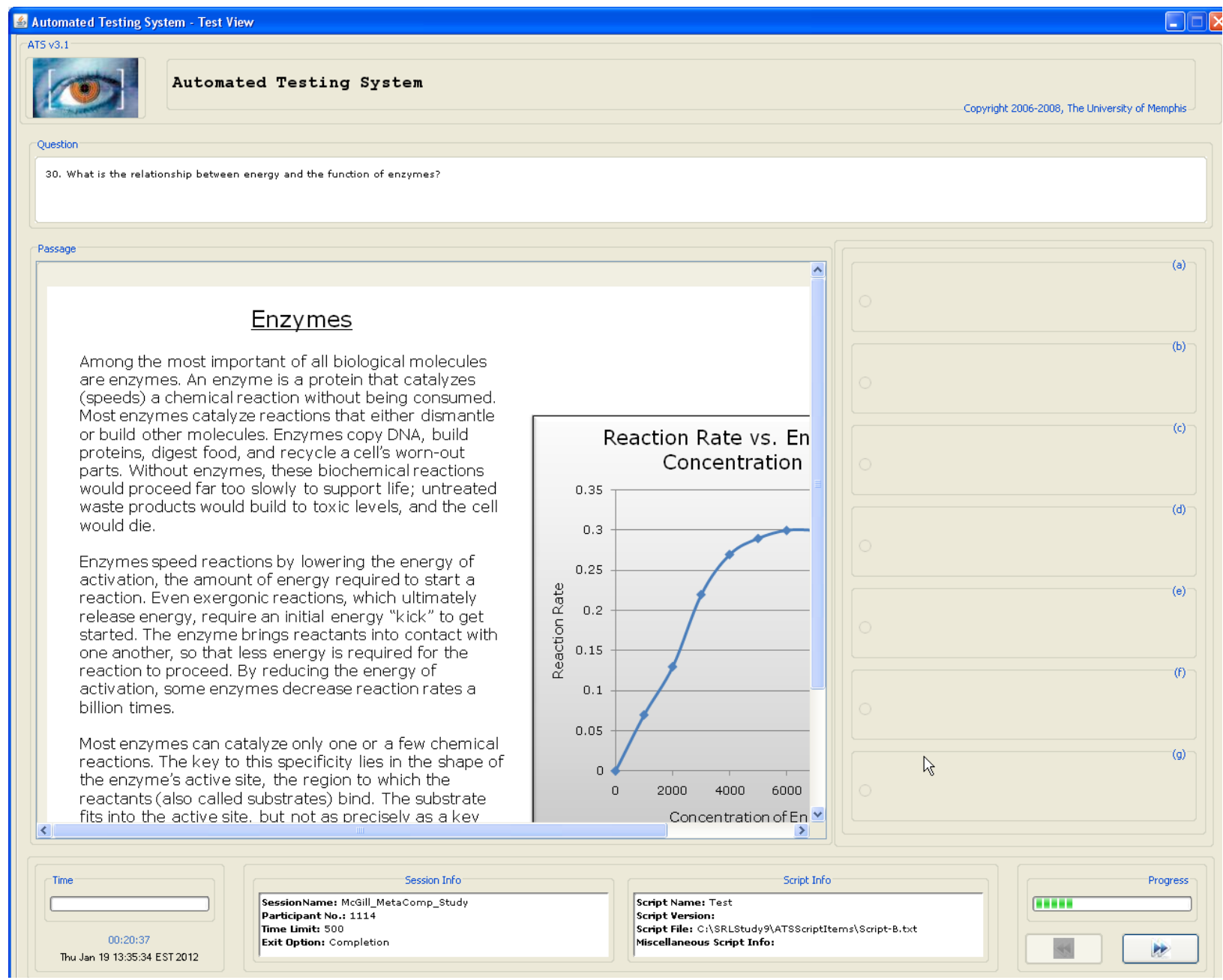

Figure 1. Screenshot of multimedia learning environment. This page on enzymes contained a conceptual discrepancy within the text between the first and last sentences in the $2^{\text {nd }}$ paragraph. 
Appendix A

CAEB Instrument

\begin{tabular}{l|l|l|l|l|l|l|l|r}
\hline \multicolumn{7}{c}{ Variability of Knowledge } \\
\hline Stable* & 1 & 2 & 3 & 4 & 5 & 6 & 7 & Unstable \\
\hline Dynamic & 1 & 2 & 3 & 4 & 5 & 6 & 7 & Static \\
\hline Temporary & 1 & 2 & 3 & 4 & 5 & 6 & 7 & Permanent \\
\hline Flexible & 1 & 2 & 3 & 4 & 5 & 6 & 7 & Inflexible \\
\hline Completed* & 1 & 2 & 3 & 4 & 5 & 6 & 7 & Uncompleted \\
\hline Refutable & 1 & 2 & 3 & 4 & 5 & 6 & 7 & Irrefutable \\
\hline Open & 1 & 2 & 3 & 4 & 5 & 6 & 7 & Closed \\
\hline
\end{tabular}

Texture of Knowledge

\begin{tabular}{l|l|l|l|l|l|l|l|r}
\hline Confirmable & 1 & 2 & 3 & 4 & 5 & 6 & 7 & Unconfirmable \\
\hline Definite & 1 & 2 & 3 & 4 & 5 & 6 & 7 & Ambiguous \\
\hline Exact & 1 & 2 & 3 & 4 & 5 & 6 & 7 & Vague \\
\hline Objective & 1 & 2 & 3 & 4 & 5 & 6 & 7 & Subjective \\
\hline Precise & 1 & 2 & 3 & 4 & 5 & 6 & 7 & Imprecise \\
\hline Sorted & 1 & 2 & 3 & 4 & 5 & 6 & 7 & Unsorted \\
\hline Structured & 1 & 2 & 3 & 4 & 5 & 6 & 7 & Unstructured \\
\hline Superficial & 1 & 2 & 3 & 4 & 5 & 6 & 7 & Profound \\
\hline Discovered & 1 & 2 & 3 & 4 & 5 & 6 & 7 & Negotiated \\
\hline Absolute & 1 & 2 & 3 & 4 & 5 & 6 & 7 & Relative \\
\hline
\end{tabular}

*Reverse coded 